\title{
KEPEMIMPINAN, KOMPETENSI DAN KINERJA PENGARUHNYA TERHADAP PENGEMBANGAN KARIR APARATUR DI KOTA PALEMBANG
}

\author{
Atika Dewi \\ Ditreskrimum Polda Sumatera Selatan \\ Email : atikadewi19@gmail.com
}

Fakhry Zamzam

Program Magister Universitas Indo Global Mandiri Palembang

Email: fakhry@uigm.ac.id

DOI : 10.35908/jeg.v4i2.759

Received: May 11, 2019, Revised: June 11, 2019, Accepted: July 09, 2019

\begin{abstract}
This research discussed Leadership, Competence and Performance on civil servants' Career Development in Palembang City. With the aim of whether or not there was an influence of Leadership, Competence and Performance on civil servants' Career Development in Palembang City. The population used in this research was Civil Servants (ASN) at the Secretariat Staff in the Government of Palembang City. The sample in this research was 100 respondents. The data analysis technique used was Structural Equation Modeling (SEM). The results of test proved that: 1). Partially the results revealed that there was a significant and positive influence between Leadership, Competence and Performance on civil servants'Career Development in the City of Palembang.2). Simultaneously Career Development was influenced positively and significantly by the Leadership variable, Competence and Performance.
\end{abstract}

Keywords:leadership, competence, performance, civil servants' career development, Palembang city.

\begin{abstract}
ABSTRAK
Penelitian ini membahas tentang Kepemimpinan, Kompetensi dan Kinerja terhadap Pengembangan Karir Aparatur di Kota Palembang. Dengan tujuan apakah ada pengaruh Kepemimpinan, Kompetensi dan Kinerja terhadap Pengembangan Karir Aparatur di Kota Palembang. Populasi yang digunakan dalam penelitian ini adalah Pegawai Negeri Sipil (ASN) pada Staf Sekretariat di Pemerintah Kota Palembang. Sampel yang digunakan dalam penelitian ini sebanyak 100 responden. Teknik analisa data yang digunakan adalah Structural Equation Modeling (SEM). Hasil pengujian membuktikan bahwa: 1).Secara parsial didapatkan hasil bahwa ada pengaruh yang signifikan dan positif antara Kepemimpinan, Kompetensi dan Kinerja terhadap Pengembangan KarirAparatur di Kota Palembang.2).Secara simultan terhadap Pengembangan Karir dipengaruhi secara langsung positif dan signifikan oleh variabel Kepemimpinan, Kompetensi dan Kinerja.
\end{abstract}

Kata kunci: Kepemimpinan, Kompetensi, Kinerja, Pengembangan Karir Aparatur

\section{Pendahuluan}

\subsection{Latar Belakang}

Kepemimpinan itu esensinya
adalah pertanggungjawaban Masalah, Kepemimpinan Daerah masih sangat baik untuk diteli karena tiada habisnya untuk dibahas di sepanjang Pemerintahan tetap berdiri di Indonesia. Terlebih pada zaman otonomi daerah dengan berbagai cara para calon-calon pemeimpinan daerah berupaya merebut simpati masyarakat dan aparatur untuk mendukung keinginannya menjadi pemimpin Daerah/Kepala Daerah baik 
Gubernur, bupati dan walikota, dimana system pilkada dilaksanakan secara langsung bukan tidak mungkin akan timbul kecurangan-kecurangan pada pelaksanaannya yang akhirnya masyarakat juga yang dirugikan di dalam praktek Pemerintahan yang berjalan, situasi akan semakin buruk saja jika moral dan mental para pemimpin daerah hanya mementingkan diri sendiri menghitung untung/ruginya maka akan semakin sulit mencari pemimpin yang baik (good leader).

Lebih jauh kepemimpinan daerah yang tidak amanah akan mempengaruhi pengembangan karir bawahan dan kompetensi aparatur, Pemimpin Daerah tidak lagi melihat latar belakang aparatur baik pengalaman, pendidikan maupun lamanya pengabdian, mereka bercermin apakah aparatur dimaksud termasuk dalam kelompok pendukung/tim sukses pada waktu pilkada atau indpenden sesuai dengan aturannya. Dan pada gilirannya aparatur akan tunduk pada Pemenang pilkada apapun konsekuensinya, dimanfaatkan atau terlibas dalam kancah Pemerintahan.

Kepemimpinan Daerah Kota Palembang belum mencerminkan pemimpin yang baik terhadap pembinaan aparatur, hal ini terlihat dari tindakkannya memutasikan pada awal kepemimpinannya tanpa alasan yang jelas. Kepemimpinan yang diterapkan oleh walikota Palembang secara otokrasi di duga akan mempengaruhi kebebasan berkreasi dan berafiliasi kepada bawahan, sehingga diidentifikasi mempengaruhi pengembangan karir aparatur.

Kepemimpinan yang diterima para aparatur yang terlibat dalam tim sukses pilkada berdampak pada promosi jabatan yang belum tentu mempunyai kompetensi di bidangnya, diduga akan mempengaruhi Kinerja. Kurangnya perhatian dari pimpinan atas hasil kerja bawahan, sehingga menimbulkan rasa ketidak puas para aparatur dan akhirnya diduga akan mempengaruhi perilaku aparatur.

Pembagian tugas pada bawahan yang tidak jelas dan sewaktu-waktu terjadinya pergantian jabatan diduga akan mempengaruhi pengembangan karir aparatur. Lingkungan kerja yang kurang kondusif antara sesama aparatur dan pimpinan sehingga menimbulkan ketidak puasan dan akhirnya diidentifikasi mempengaruhi perilaku aparatur dalam memotivasi diri.

Ancaman sanksi jabatan bagi aparatur yang tidak loyal kepada pimpinan, di duga mempengaruhi kinerja aparatur dalam pengembangan karirnya. Dengan dasar loyalitas kepada pimpinan tidak menjamin aparatur memiliki kompetensi yang sesuai dengan kedudukan dan jabatannya di duga akan mempengaruhi kinerja.

\subsection{Rumusam Masalah}

Dari latar belakang yang sudah peneliti jelaskan di atas maka rumusan masalah dalam penelitian ini adalah :

1) Apakah terdapat pengaruh antara Kepemimpinan terhadap Pengembangan Karir Aparatur di Kota Palembang?

2) Apakah terdapat pengaruh antara Kompetensi terhadap Pengembangan Karir Aparatur di Kota Palembang?

3) Apakah terdapat pengaruh antara Kinerja terhadap Pengembangan Karir Aparatur di Kota Palembang?

4) Apakah terdapat pengaruh antara Kepemimpinan, Kompetensi dan Kinerja secara bersama-sama terhadap 
Pengembangan Karir Aparatur di Kota Palembang?

\subsection{Tujuan Penelitian}

1) Apakah ada pengaruh antara Kepemimpinan terhadap Pengembangan Karir Aparatur di Kota Palembang

2) Apakah ada pengaruh antara Kompetensi terhadap Pengembangan Karir Aparatur di Kota Palembang

3) Apakah ada pengaruh antara Kinerja terhadap Pengembangan Karir Aparatur di Kota Palembang

4) Apakah ada pengaruh antara Kepemimpinan, Kompetensi dan Kinerja secara bersama-sama terhadap Pengembangan Karir Aparatur di Kota Palembang

\subsection{Metode Penelitian}

Metode yang digunakan adalah metode survey deskriptif dan survey verifikatif yang dilaksanakan melalui pengumpulan data di lapangan dan informasi langsung dari sampel, bila kita melihat dari ekspalanasinya, penelitian ini merupakan penelitian assosiatif, dimana dalam penelitian ini terdapat variabel yang berhubungan dan dapat mempengaruhi variabel lain. (Sekaran, 2003:161)

Teknik pengumpulan data penelitian untuk mendapatkan data primer dengan menggunakan instrumen penelitian berisi sejumlah pernyataan tertutup dan terstruktur untuk dijawab responden. Metode pengumpulan data yang digunakan dalam penelitian ini adalah sebagai berikut :

\section{1) Metode Kuesioner}

Yaitu dengan membuat instrumen penelitian dan menyebarkan kuesioner berupa daftar pernyataan, untuk memperoleh data primer secara langsung dari subjek penelitian. Kuesioner yang digunakan dalam penelitian ini merupakan angket langsung, yaitu kuesioner yang secara langsung diisi oleh responden.

\section{2) Metode Wawancara}

Yaitu melakukan kegiatan memberikan pertanyaan secara lisan kepada responden atau nara sumber yang berkompeten pada bidang yang diteliti, untuk mendapatkan data sekunder. Sebelumnya disiapkan dapat terlebih dahulu questioners guide sebagai arah bagi peneliti dalam mengajukan pertanyaan yang akan disampaikan. Penentuan responden yang dipilih dilakukan melalui pendekatan Purposive sampling dengan tujuan agar responden terpilih sesuai dengan kriteria yang sejalan dengan kebutuhan data dan informasi.

Penelitian ini menggunakan teknik analisis data kuantitatif berupa analisis statistika deskriptif dan analisis statistika inferensial, yakni sebagai berikut:

a. Statistika deskriptif adalah statistik yang digunakan untuk menganalisis data dengan cara mendiskripsikan atau menggambarkan data yang telah terkumpul sebagaimana adanya tanpa bermaksud mengambil kesimpulan yang berlaku untuk umum atau generalisasi (Sugiyono,2012:199).

b. Statistika inferensial (sering juga disebut statistik induktif atau statistik probabilitas) adalah teknis statistik yang digunakan untuk menganalisis data sampel dan hasilnya diberlakukan untuk populasi.(Sugiyono, 2012:201).

Analisis penelitian ini menggunakan variabel moderator sebagai variabel antara atau mediasi, fungsinya sebagai mediasi antara variabel 
independen dan variabel dependen. Variabel kompetensi dan kompensasi sebagai eksogen variabel dimediasi oleh variabel Pengembangan Karir.

$$
\text { Karenanya dalam penelitian }
$$
menggunakan software Structural Equation Modeling (SEM), yaitu merupakan gabungan dari dua metode statistik yang terpisah yaitu analisis faktor dan model persamaan simultan.

\section{Kajian Pustaka}

\subsection{Pengertian Kepemimpinan}

Secara sederhana "Kepemimpinan" menurut Yaverbaum \& Sherman (2008) bisa didefinisikan "Leadership is act of gaining cooperation from people in order to accomplish something". Kepemimpinan adalah tindakan mendapatkan kerja sama dari orang untuk mencapai sesuatu.Lebih lanjut "Kepemimpinan" menurut Bush (2000) I mean influencing others actions in achieving desirable ends adalah "Kepemimpinan adalah mempengaruhi tindakan orang lain untuk mencapai tujuan akhir yang diharapkan".

\subsection{Pengertian Kompetensi}

Kompetensi adalah karakteristik dasar dari seseorang yang memungkinkan mereka mengeluarkan kinerja superior dalam pekerjaannya. Menurut Trotter dalam Saifuddin (2004) mendefinisikan bahwa seorang yang berkompeten adalah orang yang dengan keterampilannya mengerjakan pekerjaan dengan mudah, cepat, intuitif dan sangat jarang atau tidak pernah membuat kesalahan.

Boyatzis dalam Hutapea dan Nurianna Thoha (2001) kompetensi adalah kapasitas yang ada pada seseorang yang bisa membuat orang tersebut mampu memenuhi apa yang disyaratkan oleh pekerjaan dalam suatu organisasi sehingga organisasi tersebut mampu mencapai hasil yang diharapkan. Webster.s Ninth New

\section{Collegiate Dictionary dalam Sri} Lastanti (2005) mendefinisikan kompetensi adalah ketrampilan dari seorang ahli. Di mana ahli didefinisikan sebagai seseorang yang memiliki tingkat keterampilan tertentu atau pengetahuan yang tinggi dalam subyek tertentu yang diperoleh dari pelatihan dan pengalaman.

\subsection{Kinerja}

Kemampuan bekerja untuk membangun atau memelihara keramahan, hubungan yang hangat atau komunikasi jaringan kerja dengan seseorang, atau mungkin suatu hari berguna dalam mencapai tujuan kerja..

Konsep kerja didefinisikan sebagai proses penciptaan atau pembentukan nilai baru (tambah) pada suatu unit sumber daya. Kerja dapat dihubungkan dengan kesenangan atau kepentingan diri sendiri dan dapat pula dianggap sebagai komoditas yang bisa digunakan oleh orang lain bahkan dijadikan komoditas pasar kerja. (Ndraha, 2002 : 40-41).

Kinerja merupakan suatu fungsi dari motivasi dan kemampuan untuk meyelesaikan tugas atau pekerjaan seseorang, yang sepatutnya memiliki derajat kesediaan dan kemampuan tertentu, kesediaan dan ketrampilan seseorang tidaklah cukup efektif untuk mengerjakan sesuatu tanpa memahami tentang apa yang akan dikerjakan dan bagaimana mengerjakannya.

Kinerja merupakan perilaku nyata yang ditampilkan setiap orang sebagai prestasi kerja yang dihasilkan oleh karyawan sesuai dengan perannya. Kinerja 
karyawan merupakan hal yang sangat penting dalam upaya perusahaan untuk mencapai tujuannya. Ilyas(2001:34) menerjemahkan performance menjadi unjuk kerja, sedangkan Wahyudi (2000:96) menerjemahkan menjadi prestasi kerja

\subsection{Pengembangan Karier}

Teori perkembangan karir (development career choice theory) dari Eli Ginzberg et. al. yang mengatakan bahwa anak dan remaja melewati tiga tahap pemilihan karir: fantasi, tentative dan relistis (Ginzberg, 1972 ; Ginzberg dkk., 1951). Saat ditanya "mau jadi apa kalau sudah besar", anak kecil mungkin menjawab "dokter" "pahlawan", "guru", "bintang film", "bintang olahraga" atau sejumlah pekerjaan lainnya. Pada saat masih kecil, masa depan terkesan dapat memberikan jutaan kesempatan. Ginzberg berargumentasi bahwa hingga usia 11 tahun seorang anak masih dalam tahap fantasi dari pemilihan karir. Dari umur 11 hingga 17 tahun, remaja ada dalam tahap tentative dari perkembangan karir, sebuah transisi dari tahap pengambilan keputusan realistis dari masa dewasa muda. Ginzberg percaya bahwa kemajuan remaja terlihat mulai dari mengevaluasi minat mereka (11 hingga 12 tahun) lalu mengevaluasi kemampuan mereka (13 hingga 14 tahun) sampai mengevaluasi nilai mereka (15 hingga 16 tahun). Pemikiran berubah dari yang kurang subyektif hingga pemilihan karir yang lebih realistis pada usia 17 dan 18 tahun. Ginzberg menyebut usia 17 dan 18 tahun hingga awal 20-an sebagai tahap realistis dalam pemilihan karir. Selama masa ini, tiap orang secara ekstentif mencoba karir yang mungkin, lalu memfokuskan diri pada satu bidang, dan akhirnya memilih pekerjaan tertentu dalam karir tersebut (seperti menjadi dokter umum, atau ahli bedah ottopedik, dalam karir kedokteran.

Ginzberg juga menyimpulkan bahwa pengambilan keputusan dalam pilihan karier itu berlangsung sepanjang hayat, sebagai refleksi dari perubahan minat dan tujuan-tujuan, serta keadaan atau tekanan yang berlangsung dalam kehidupan seseorang.Konsep ini sebagai reaksi edukatif Ginzberg atas kelemaham awal tentang batasan umur masa realistis dari teori yang dibangunnya.Sehingga diakhir pendapatnya, Ginzberg (Munandir, 1996:92) menyatakan bahwa "pemilihan pekerjaan merupakan proses pengambilan keputusan yang berlangsung seumur hidup bagi mereka yang mencari kepuasan dari pekerjaannya. Keadaan ini mengharuskan mereka berulang-ulang melakukan penilaian kembali, dengan maksud mereka dapat lebih mencocokkan tujuan-tujuan karier yang terus berubah-ubah dengan kenyataan dunia kerja”. (Ginzberg, 1984,180).

\section{Hasil dan Pembahasan}

\subsection{Populasi dan Sampel}

Pegawai Negeri Sipil (ASN) pada staf sekretariat sebagai objek penelitian mewakili aparatur sipil Negara pada Pemerintah Kota Palembang. Sehingga penelitian ini menggunakan sampel jenuh, seluruh pejabat dan staf pada dinas-dinas sebanyak 100 orang adalah populasi sekaligus sebagai sampel. Seluruh populasi tersebut kemudian dijadikan sampel penelitian sehingga penelitian ini akan menggunakan sampel jenuh. Menurut Sugiyono (2012:126) sampel jenuh juga sering diartikan sampel yang sudah maksimum, ditambah berapapun tidak 
merubah keterwakilan. Distribusi populasi dan sampel penelitian disertasi dapat dilihat dalam tabel 3.1 sebagaimana berikut ini:

Tabel 3.1

\section{Distribusi Populasi dan Sampel Penelitian}

\begin{tabular}{|c|c|c|c|c|c|}
\hline No. & Unit Kerja & $\begin{array}{l}\text { Jumlah } \\
\text { Pegawai }\end{array}$ & $\begin{array}{l}\text { Persentase } \\
\text { Pegawai }\end{array}$ & $\begin{array}{c}\text { Jumlah } \\
\text { Sampel Uji } \\
\text { Coba } \\
\text { Instrumen }\end{array}$ & Jumlah \\
\hline 1 & $\begin{array}{l}\text { Staf Sekretaris } \\
\text { Daerah }\end{array}$ & 2 & $\begin{array}{c}5 / 130= \\
0.03\end{array}$ & 2 & 2 \\
\hline 2 & $\begin{array}{l}\text { Bagian } \\
\text { Keuangan }\end{array}$ & 8 & $\begin{array}{c}10 / 130= \\
0.07\end{array}$ & 8 & 8 \\
\hline 3 & Bagian Hukum & 8 & $\begin{array}{c}10 / 130= \\
0.07\end{array}$ & 8 & 8 \\
\hline 4 & Bagian Ortala & 8 & $\begin{array}{c}10 / 130= \\
0.07\end{array}$ & 8 & 8 \\
\hline 5 & Bagian Sosmas & 8 & $\begin{array}{c}10 / 130= \\
0.07\end{array}$ & 8 & 8 \\
\hline 6 & $\begin{array}{l}\text { Bagian } \\
\text { Perekonomian }\end{array}$ & 8 & $\begin{array}{c}10 / 130= \\
0.07\end{array}$ & 8 & 8 \\
\hline 7 & Bagian Umum & 8 & $\begin{array}{c}10 / 130= \\
0.07\end{array}$ & 8 & 8 \\
\hline 8 & $\begin{array}{l}\text { Bagian } \\
\text { Perlengkapan }\end{array}$ & 8 & $\begin{array}{c}10 / 130= \\
0.07\end{array}$ & 8 & 8 \\
\hline 9 & Bagian Humas & 2 & $\begin{array}{c}5 / 130= \\
0.03\end{array}$ & 2 & 2 \\
\hline 10 & $\begin{array}{l}\text { Bagian } \\
\text { Sekretariat } \\
\text { Korpri }\end{array}$ & 8 & $\begin{array}{c}10 / 130= \\
0.07\end{array}$ & 8 & 8 \\
\hline 11 & Bagian KPPT & 8 & $\begin{array}{c}10 / 130= \\
0.07\end{array}$ & 8 & 8 \\
\hline 12 & $\begin{array}{l}\text { Badan } \\
\text { Pengelola } \\
\text { Keuangan } \\
\text { Daerah }\end{array}$ & 8 & $\begin{array}{c}10 / 130= \\
0.07\end{array}$ & 8 & 8 \\
\hline 13 & $\begin{array}{l}\text { Bagian } \\
\text { Pembvangunan }\end{array}$ & 8 & $\begin{array}{c}10 / 130= \\
0.07\end{array}$ & 8 & 8 \\
\hline 14 & $\begin{array}{l}\text { Staf pada staf } \\
\text { Ahli Setda }\end{array}$ & 8 & $\begin{array}{c}10 / 130= \\
0.07\end{array}$ & 8 & 8 \\
\hline & J U M L A H & 100 & & 100 & 100 \\
\hline
\end{tabular}

\subsection{Metode Analisis Data}

Metode analisis yang digunakan dalam penelitian ini menggunakan
Structural Equation Modeling (SEM). SEM merupakan teknik multivariate yang mengkombinasikan aspek regresi berganda dan analisis faktor untuk mengestimasi serangkaian hubungan ketergantungan secara simultan (Hair et al, 2008).

Pengujian hipotesis dilakukan dengan menggunakan program SEM Amos version 20 untuk menganalisis hubungan kausalitas dalam model struktural yang diusulkan.

Analisis SEM, menurut pendapat Waluyo (2011:1) adalah sekumpulan teknikteknik statistik yang memungkinkan pengujian sebuah rangkaian hubungan yang relatif "rumit" secara simultan. Hubungan rumit yang dimaksud adalah rangkaian yang dibangun antara satu atau beberapa variabel dependen dengan satu beberapa variabel independen.

Sebelum melakukan pengujian model struktural dengan pendekatan SEM yang menggunakan estimate maximum likelihood, ada beberapa asumsi dasar yang harus dipenuhi terlebih dahulu yaitu :

\section{1)Data Kontinous Interval}

Penelitian ini menggunakan Skala Likert untuk mendapatkan data kontinous interval. Menurut Uma Sekaran Skala Likert akan menghasilkan data interval.

Data interval adalah data yang jaraknya sama, tetapi tidak mempunyai nilai nol obsolut (mutlak). Pada data ini walaupun datanya nol tetapi masih mempunyai nilai. Dalam penelitian sosial yang instrumennya menggunakan Skala Likert, Gulman, Semantic differential dan Thurstone data yang diperoleh adalah data interval.

2)Asumsi Kecukupan Sampel 
Besaran ukuran sampel memiliki peran penting dalam interpretasi hasil analisis SEM. Penelitian ini akan menggunakan sampel jenuh, dimana semua populasi dijadikan sampel. Sampel yang harus dipenuhi dalam permodelan ini berkisar antara 100 hingga 250 sampel.

Ukuran sampel minimal menurut Hair et.al seperti dikutip oleh Ferdinand (2002:43) yang menyatakan bahwa ukuran sampel (data observasi) yang sesuai adalah berjumlah antara 100 sampai 200 atau minimal menggambarkan perbandingan 5 dan maksimal 10 yakni 100 sampai 200.

Salah satu cara menentukan besaran sampel yang memenuhi hitungan itu adalah yang dirumuskan oleh Slovin (Steph Ellen, eHow Blog, 2010; dengan rujukan Principles and Methods of Research; Ariola et al. (eds.); 2006) sebagai berikut :

$$
\mathrm{n}=\mathrm{N} /(1+\mathrm{Ne} 2)
$$

dimana:

$\mathrm{n} \quad=$ Number of samples (jumlah

$\mathrm{N}=$ Total population (jumlah seluruh anggota populasi)

$\mathrm{e}=$ Error tolerance (toleransi terjadinya galat; taraf signifikansi)

\section{3)Uji Normalitas}

SEM mensyaratkan data terdistribusi normal atau dianggap berdistribusi normal, uji normalitas pada SEM mempunyai dua tahapan. Tahapan pertama menguji normalitas untuk setiap variabel sedangkan tahap kedua adalah pengujian normalitas semua variabel secara bersama-sama.

Pertama adalah menghitung cr dari tingkat kemecengan (skweness) sebuah variabel. Kedua, menghitung cr dari tingkat keruncingan (kurtosis) sebuah variabel. Dengan demikian sebuah data distribusi dikatakan normal jika angka cr skweness atau angka cr kurtoses ada di antara $-2,58$ sampai $+2,58$ (Santoso Singgih 2011:78,79).

\section{4) Asumsi Outliers}

Outliers adalah observasi atau data yang memiliki karakteristik unik yang terlihat sangat berbeda jauh dari observasiobservasi lainnya dan muncul dalam bentuk nilai ekstrim, baik untuk sebuah variabel tunggal atau variabel kombinasi (Hair et al. dalam Ferdinand, 2002: 97). Dalam analisis multivarariate adanya outliers dapat diuji dengan statistik chi square terhadap nilai mahalanobis distance square pada tingkat signifikansi 0,001 dengan degree of freedom sejumlah variabel yang digunakan dalam penelitian (Ferdinand, 2002: 103), dalam hal ini variabel yang dimaksud jumlah item pengukuran pada model, bila terdapat observasi yang mempunyai nilai mahalanobis distance square yang lebih besar dari chi Square maka observasi tersebut dikeluarkan dari analisis.

Umumnya perlakuan terhadap outliers adalah dengan mengeluarkannya dari data dan tidak diikutsertakan dalam perhitungan berikutnya. Bila tidak terdapat alasan khusus untuk mengeluarkan outliers, maka observasi dapat diikutsertakan dalam analisis selanjutnya. Evaluasi outliers ini dilakukan dengan bantuan program komputer program Amos.

\section{5)Asumsi Linearitas}

Uji linearitas bertujuan untuk mengetahui apakah dua variabel 
mempunyai hubungan yang linear atau tidak secara signifikan. Uji ini biasanya digunakan sebagai prasyarat dalam analisis korelasi atau regresi linear. Pengujian pada SPSS dengan menggunakan test for linearity dengan pada taraf signifikansi 0,05 . Dua variabel dikatakan mempunyai hubungan yang linear bila signifikansi linearity kurang dari 0,05.

\subsection{Uji Validitas Kuesioner.}

Untuk menguji validitas digunakan uji korelational product moment dari Pearson Correlation, dengan cara mengkorelasikan nilai $r$ product moment setiap butir instrumen dengan jumlah total skor setiap butir instrumen dari seluruh jawaban responden. Nilai $r$ product moment ini lalu dikonsultasikan dengan nilai $\mathrm{r}$ product moment kritis pada tabel statistik dengan $\mathrm{n}=30 \alpha=0.05$. Nilai $r$ tabel diperoleh 0.361.Dengan demikian jika nilai $r$ hitung $\geq$ dari 0,361 berati butir kuesioner tersebut valid. Dari seluruhnya baik variabel kepemimpinan, kinerja, kepemimpinan dan pengembangan karier terbukti valid.

\section{4,Uji Reliabilitas Kuesioner.}

Berdasarkan nilai Nilai Cronbach's Alpha untuk Uji Reliabilitas Kuesioner variabel kepemimpinan, kinerja, kepemimpinan dan pengembangan karier terbukti reliable dan bisadilanjutkan dalam penelitian.

Analisis selanjutnya adalah analisis Structural Equation Modelling (SEM) secara full model (tanpa melibatkan indikator yang tidak valid). Analisis hasil pengolahan data pada tahap full model SEM dilakukan dengan melakukan uji kesesuaian dan uji statistik.
Untuk menguji kelayakan model secara keseluruhan (Ful Model) dilakukan dengan memperhatikan hasil perhitungan Goodness of Fit Statistics dengan Software LISREL 8.5. Adapun pengujiannya merujuk pada kriteria model fit yang terdapat pada tabel Goodness $\boldsymbol{O} \boldsymbol{f}$ Fit Index berikut :

Tabel 3.2.

\section{Goodness Of Fit Index}

\begin{tabular}{|c|c|c|c|c|c|}
\hline No & $\begin{array}{c}\text { Goodness } O f \\
\text { Fit Index }\end{array}$ & Nilai & $\begin{array}{c}\text { Cut off } \\
\text { Value } \\
\text { (Nilai } \\
\text { Batas) }\end{array}$ & Kriteria & Ket. \\
\hline \multirow{2}{*}{1.} & Chi-Square & 45,50 & $<\alpha . d f$ & \multirow{2}{*}{ Good Fit } & \multirow{2}{*}{ Tidak Fit } \\
\hline & Probability & 0,035 & $>0,05$ & & \\
\hline 2. & RMSEA & 0,073 & $\begin{array}{c}\leq 0,08 \\
0,08- \\
0,10\end{array}$ & $\begin{array}{l}\text { Good Fit } \\
\text { Merginal } \\
\text { Fit }\end{array}$ & Good Fit \\
\hline 3. & NFI & 0,86 & $\begin{array}{c}\geq 0,90 \\
0,80- \\
0,89\end{array}$ & $\begin{array}{c}\text { Good Fit } \\
\text { Merginal } \\
\text { Fit }\end{array}$ & $\begin{array}{c}\text { Merginal } \\
\text { Fit }\end{array}$ \\
\hline 4. & $\begin{array}{l}\text { TLI atau } \\
\text { NNFI }\end{array}$ & 0,91 & $\begin{array}{c}\geq 0,90 \\
0,80- \\
0,89\end{array}$ & $\begin{array}{l}\text { Good Fit } \\
\text { Merginal } \\
\text { Fit }\end{array}$ & Good Fit \\
\hline 5. & CFI & 0,94 & $\begin{array}{c}\geq 0,90 \\
0,80- \\
0,89\end{array}$ & $\begin{array}{c}\text { Good Fit } \\
\text { Merginal } \\
\text { Fit }\end{array}$ & Good Fit \\
\hline 6. & IFI & 0,94 & $\begin{array}{c}\geq 0,90 \\
0,80- \\
0,89\end{array}$ & $\begin{array}{l}\text { Good Fit } \\
\text { Merginal } \\
\text { Fit }\end{array}$ & Good Fit \\
\hline 7. & RMR & 0,036 & $\begin{array}{c}\leq 0,05 \\
0,05- \\
0,10\end{array}$ & $\begin{array}{l}\text { Good Fit } \\
\text { Merginal } \\
\text { Fit }\end{array}$ & Good Fit \\
\hline 8. & GFI & 0,92 & $\begin{array}{c}\geq 0,90 \\
0,80- \\
0,89\end{array}$ & $\begin{array}{c}\text { Good Fit } \\
\text { Merginal } \\
\text { Fit }\end{array}$ & Good Fit \\
\hline 9. & AGFI & 0,84 & $\begin{array}{c}\geq 0,90 \\
0,80- \\
0,89\end{array}$ & $\begin{array}{l}\text { Good Fit } \\
\text { Merginal } \\
\text { Fit }\end{array}$ & $\begin{array}{c}\text { Merginal } \\
\text { Fit }\end{array}$ \\
\hline
\end{tabular}

Sumber : Ghozali (2008) dan Hasil Olah Data Penelitian (2017) 
Berdasarkan Tabel 4.16 dan hasil analisis dari Lisrel di atas menunjukan bahwa model secara keseluruhan (Ful Model) mempunyai delapan criteria goodness of fit yang baik. Hal ini menunjukan bahwa model secara keseluruhan (Ful Model)yang dihasilkan mempunyai goodness of fit yang baik, yang berarti seluruh model struktural yang dihasilkan merupakan model yang Fit atau cocok, sehingga dapat dilanjutkan dalam analisis selanjutnya.

Hasil pendugaan untuk analisis full model SEM berdasarkan t-value ditampilkan pada Gambar berikut :

\section{Gambar 3.1}

\section{Hasil Pendugaan Full Model berdasarkan t-value}

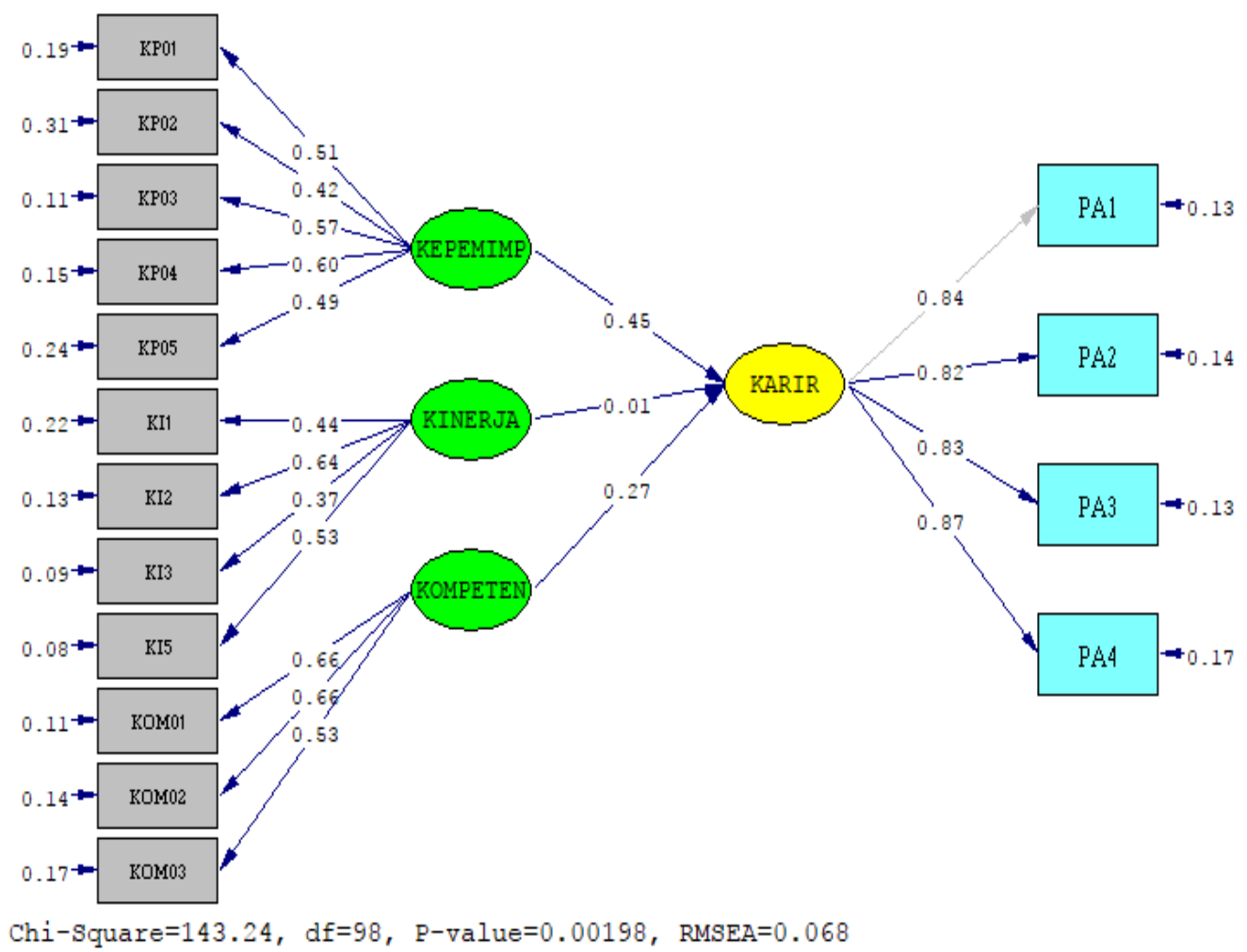

Sumber : Data primer diolah peneliti dengan SEM 2017

Berdasarkan Gambar 4.10 di atas dapat diketahui bahwa hanya satu parameter pada Full Model yang signifikan (nilai t-hitung yang lebih besar dari 1,96), yaitu Kepemimpinan berpengaruh positif dan signifikan terhadap Pengembangan Karir pada taraf kepercayaan sebesar $95 \%$.
Sedangkan Kompetensi dan Kinerja berpengaruh positif dan signifikan terhadap Pengembangan Karir.

Hasil dugaan untuk analisis full model SEM berdasarkan standar loading ditampilkan pada Gambar 4.11 berikut : 


\section{Gambar 3.2}

\section{Hasil Pendugaan Full Model berdasarkan Standar Loading}

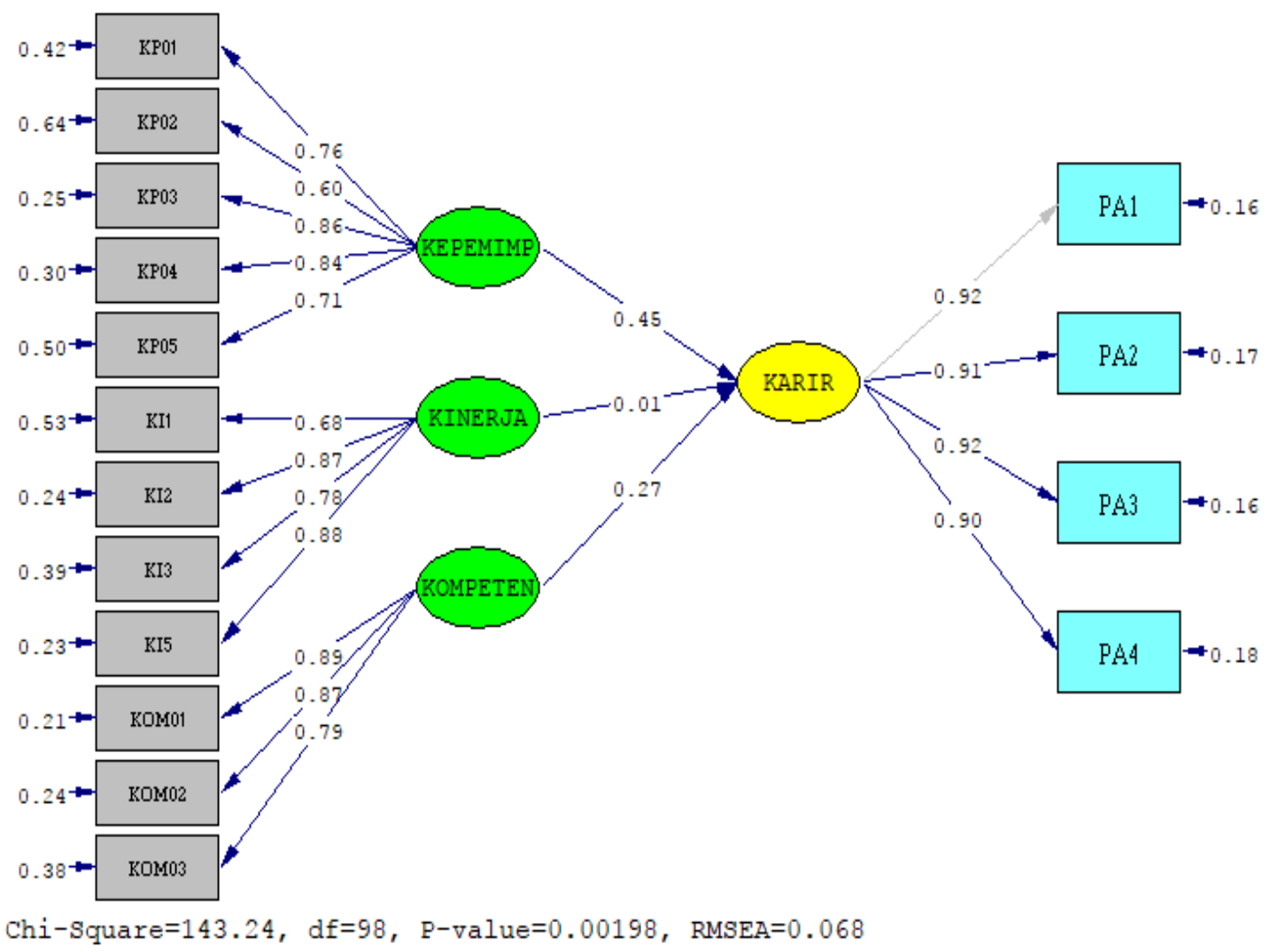

Sumber : Data primer diolah peneliti dengan SEM 2017

Berdasarkan hasil standar loading di atas, diperoleh persamaan struktural sebagai berikut.

\section{Persamaan Sub-Struktural :}

$$
\mathrm{PA}=0.45 * \mathrm{KP}+0.27 \mathrm{KOM}
$$

Berdasarkan model sub-struktural di atas dapat di jelaskan bahwa Pengembangan Karir dipengaruhi secara langsung oleh variabel Kepemimpinan, Kompetensi dan Kinerja secara positif dan signifikan masing-masing sebesar 0,45 dan 0,27 berpengaruh positif dan signifikan pada taraf kepercayaan 95\%. Hal ini berarti bahwa semakin baik Kepemimpinan, Kompetensi dan Kinerja maka Pengembangan Karir Aparatur di Kota Palembang akan semakin meningkat.

\section{Persamaan Struktural :}

$$
\begin{gathered}
\mathrm{PA}=0.01 * \mathrm{KI}+0.45 * \mathrm{KP}+0.27 * \mathrm{KOM} \\
+\mathrm{e}=0,73
\end{gathered}
$$

Berdasarkan model struktural di atas dapat dijelaskan bahwa Pengembangan Aparatur dipengaruhi secara langsung oleh variabel Kinerja Kepemimpinan dan Kompetensi secara positif dan signifikan masing-masing sebesar 0,73 dengan taraf kepercayaan 95\%. Hal ini berarti bahwa semakin baik Kepemimpinan, Kompetensi dan Kinerja maka Pengembangan Karir Aparatur di Kota Palembangahan semakin baik. 
suatu hubungan kausalitas dengan ouput data diolah dengan SEM sebagai berikut:

Tabel 3.3.

\subsection{Pengujian Hipotesis}

\section{Uji Hipotesis}

Setelah semua asumsi yang mendasi Structural Equation Modeling (SEM) dapat dipenuhi dan melalui confirmatory factor analysis menghasilkan model fit, selanjutnya dilakukan pengujian hipotesis sebagaimana diajukan pada bab sebelumnya.

Pengujian atas 4 hipotesis penelitian ini dilakukan berdasarkan nilai Critical Ratio (CR) dan tingkat signifikansi dari
Regression Weight Struktural Equation Model (SEM)

\begin{tabular}{|l|c|c|c|c|c|}
\hline \multicolumn{1}{|c|}{ Variabel } & Estimate & S.E & C.R & P & Label \\
\hline Karir<-- Kepemimpinan & 0.45 & .130 & $\mathbf{0 . 9 7}$ & 0.001 & \\
\hline Karir<-- Kinerja & 0.01 & .056 & $\mathbf{0 . 9 9}$ & 0.001 & \\
\hline Karir<-- Kompetensi & 0.27 & .132 & $\mathbf{0 . 8 4}$ & 0.001 & \\
\hline
\end{tabular}

Sumber: Ouput Data diolah dengan AMOS 2017

Dari hasil pengujian hipotesis pada tabel 3.3. di atas dapat diberikan penjelasan sebagai berikut:

Hipotesis $\mathrm{H}_{0}$ : Pengaruh Kepemimpinan terhadap Pengembangan Karir Aparatur di 1 Kota Palembang

$\mathrm{H}_{1}$ : Kepemimpinan berpengaruh positifdan signifikan terhadap Pengembangan Karir Aparatur di Kota Palembang

Dengan menggunakan analisis SEM, parameter estimasi untuk Pengaruh Kepemimpinan terhadap Pengembangan Karir Aparatur di Kota Palembang menunjukkan nilai CR sebesar 0,97 dengan probabilitas sebesar 0.001 lebih kecil dari 0,05. Sehingga menolak $\mathrm{H}_{0}$ dan menerima $\mathrm{H}_{1}$ dengan demikian Kepemimpinan berpengaruh positif dan signifikan terhadap Pengembangan Karir Aparatur di Kota Palembang

Hipotesis $\mathrm{H}_{0}$ : Pengaruh Kinerja terhadap Pengembangan Karir Aparatur di Kota Palembang

$\mathrm{H}_{1}$ : Kinerja berpengaruh positif dan signifikan terhadap Pengembangan Karir Aparatur di Kota Palembang

Dengan menggunakan analisis SEM, parameter estimasi untuk Pengaruh Kinerja terhadap Pengembangan Karir Aparatur di Kota Palembang menunjukkan nilai CR sebesar 0.99 dengan probabilitas sebesar 0.001 lebih kecil dari 0,05. Sehingga menolak $\mathrm{H}_{0}$ dan menerima $\mathrm{H}_{1}$ dengan demikian Kinerja berpengaruh positif dan signifikan terhadap terhadap Pengembangan Karir Aparatur di Kota Palembang

Hipotesis $\mathrm{H}_{0}$ : Pengaruh Kompetensi terhadap Pengembangan Karir Aparatur di Kota 
Palembang

$\mathrm{H}_{1}$ : Kompetensi berpengaruh positifdan signifikan terhadap Pengembangan Karir Aparatur di Kota Palembang

Dengan menggunakan analisis SEM, parameter estimasi untuk Pengaruh Kompetensi terhadap Pengembangan Karir Aparatur di Kota Palembang menunjukkan nilai CR sebesar 0.84 dengan probabilitas sebesar 0.001 lebih kecil dari 0,05. Sehingga menolak $\mathrm{H}_{0}$ dan menerima $\mathrm{H}_{1}$ dengan demikian Kompetensi berpengaruh positif dan signifikan terhadap terhadap Pengembangan Karir Aparatur di Kota Palembang

Hipotesis $\mathrm{H}_{0}$ : Pengaruh Kepemimpinan, Kinerja dan Kompetensi secara bersama4 sama terhadap Pengembangan Karir Aparatur di Kota Palembang

$\mathrm{H}_{1}$ : Pengaruh Kepemimpinan, Kinerja dan Kompetensi secara bersamasama berpengaruh positifdan signifikan terhadap Pengembangan Karir Aparatur di Kota Palembang

Hasil penelitian terhadap koefisien model structural dan kaitannya dengan hipotesis penelitian terinci dalam persamaam structural sebagai berikut:

Pengembangan Karir $(0.91)=$ Kepemimpinan $(0.97)+\operatorname{Kinerja}(0.99)$ + Kompetensi (0.84) + e(0.9). Maka $\mathrm{H}_{1}$ diterima persamaan tersebut mencerminkan adanya pengaruh secara bersama-sama antara Kepemimpinan, Kinerja dan Kompetensi terhadap Pengembangan Karir Aparatur di Kota Palembang, dan untuk besaran pengaruh 0.91 berarti ini pengaruhnya secara bersama-sama sebesar 0.91 atau sebesar $91 \%$.

\section{Kesimpulan}

\subsection{Kesimpulan}

Berdasarkan hasil analisis dan pengujian secara statistik terhadap data penelitian ini (Pengaruh Kepemimpinan, Kompetensi dan Kinerja terhadap Pengembangan Karir Aparatur di Pemerintahan Kota Palembang), dapat disimpulkan sebagai berikut:

1) Kepemimpinan berpengaruh positif dan siginifikan terhadap Pengembangan Karir Aparatur di
Pemerintahan Kota Palembang. Besarnya pengaruh kepemimpinan terhadap Pengembangan Karir sebesar 0.91, artinya semakin baik kepemimpinan maka Pengembangan Karir Aparatur di Pemerintahan Kota Palembang juga akan semakin baik, pengaruh kepemimpinan dimaksud didukung oleh Kompetensi yang dimiliki oleh Pimpinan.

2) Kompetensi berpengaruh positif dan signifikan terhadap Pengembangan Karir Aparatur Pemerintahan Kota Palemban. Pengaruh kompetensi terhadap Pengembangan Karir sebesar 
0.84. Artinya dengan penambahan kompetensi Aparatur akan mempengaruhi Pengembangan Karir Aparatur Pemerintahan Kota Palembang kompetensi akan berdampak pada Pengembangan Karir Aparatur di Kota Palembang.

3) Pengembangan Karir dipengaruhi secara langsung positif dan signifikan oleh variabel Kepemimpinan, Kompetensi dan Kinerja secara simultan. Hal ini ditunjukkan dengan nilai persamaan struktural Pengembangan Karir $=0.97$ Kepemimipinan +0.84 Kompetensi + 0.99 Kenerja $(\mathrm{R} 2=0,91)$. Hasil pengujian secara statistik dari ketiga variabel berpengaruh terhadap kinerja. Hal ini berarti bahwa semakin baik kepemimpinan dalam organisasi Pemerintah di Kota palembang tersebut dan Pengembangan Karirnya maka Kinerja Aparatur dalam memberikan pelayanan kepada Masyarakat di Kota Palembang akan meningkat.

4) Hal tersebut mengindikasikan bahwa peningkatan Kinerja di Kota Palembang akan terjadi apabila didukung adanya peningkatan secara bersama-sama antara Kepemimpinan, Kompetensi dan Kinerja.

\subsection{Saran}

1) Pimpinan secara simultan harus meningkatkan kinerjanya dengan melibatkan bawahan secara demokratis memberikan keleluasaan bawahan dalam mengembangkan karir dan secara terus menerus mendorong dan memberikan motivasi bawahannya melalui pembekalan diklat-diklat dan pelatihan kepemimpinan

2) Untuk pendelegasian tugas dan tanggung jawab bawahan perlu diperhatihan Kopmptensi yang dimiliki oleh setiap aparatur sehingga kewenangan dan tanggung jawab yang diberikan oleh atasan akanberjalan dan terlaksana dengan baik sesuai dengan harapan atasan dan perlu diperhatikan pemberian kompensasi non finansial seperti uang lembur dan reward.

3) Untuk meningkatkan kepercayaan anggota diperlukan motivasi yang tinggi dari para pengelola dan upaya untuk meningkatkan motivasi yang tinggi perlu diberikan pembekalan kepada para aparatur akan pengetahuan tentang kepemimpinan yang baik secara manajemen dalam upaya meningkatkan kinerja perlu direncanakan program kerja dan target yang ingin capai sehingga menjadi ukuran target kinerja.

\section{DAFTAR PUSTAKA}

A.Soegihartono, 2012. Pengaruh Kepemimpinan dan Kepuasan Kerja Terhadap Kinerja Dengan Mediasi Komitmen, Jurnal Fak, Ekonomi Univ, Dian Nuswantoro Semarang, Vol 3 Nomor 1.

Amstrong,M $1998 \quad$ Ferformance Management Clays, Ltd.Ives Ple, England, Anoraga

Andhika Putra Kresnandito, 2012 Pengaruh Persepsi Kepemimpinan Transformasional terhadap perilaku inovatif karyawan, Jurnal Fak, Psikologi Universitas Airlangga, Vol 1 Nomor 2.

Anoraga, (2009) Sistem kompensasi, Jakarta.penerbit Rineka cipta 
Arikunto, Suharmini, 2005, Manajemen Penelitian, Edisi Revisi, Jakarta Rineka Cipta.

Azmi, Ghani, 2010 Competency Based Human Resource Practices in Malaysian Public Sector Organization, African Journal of Business Management Bangun Wilson, 2012. Manajemen Sumber Daya Manusia, Bandung. Erlangga.

Bangun Wilson,2012. Manajemen Sumber Daya Manusia, Bandung. Erlangga.

Bass,B.M.\&R.E. Ringgo 2006. Tranformational leadership, New York, Lawrence Erbaum Associates Publisher.

Bernadin \& Rusel 2008, Human Risource Management, Universitas of California.

Boland,L.A,2005. Critical Economic Method. London George Allen and Unwin.

Bush,T. 2008. Leadership and Management Development in Education, London, A.Sage Publication Compan

Byars,Llloyd \& Rue Leslie 2006, Pengukuran Kinerja berbasis Kompetensi, Translate By Uk Sinaga 2016, Penerbit Ghalai, Indonesia.

Chaney,C.2006. TheLeader's Tool Kit Hundreads of Tips and Techniques for Developing he Skill you Need, New York, Amacom.

Collins,J,2006, Good to Great, New York, Summit.

Darlius, 2009, Disertasi Pengaruh Kepemimpinan dan kompetensi, terhadap Motivasi Implikasinya pada Kinerja Karyawan, Jakarta.Universitas Persada Indonesia. YAI.
Delahaye,B. 2011, Development Managing Learning Knowledge Capital Human Resoucess, Third Edition, Pahlan, VIC, Australia, Tidle university Press.Vol 4 (2),PP.235-241.

Firdaus, Zamzam Fakhry, 2018 Aplikasi Metodologi, Yogyakarta, Penerbit Deepublish

Gallos, Joan, 2008, Business Leadership, New Jersey John Willey \& Son

Ghozali, Imam, 2006, Analisis Multivariate Lanjutan, Semarang, Penerbit UNDIP.

Ghozali, Imam, 2008, Model Persamaan Structural, Konsep dan Aplikasi dengan Program AMOS 16, Semarang, BP Undip.

Gibson,J.L.J.M. Invencenth, et.all. 2009 Organization Bahavior, Structure, Process, Thirteenth Edition, New York Mcgraw Hill

Gill,R. 2009. Theory and Practice of Leadership, New York,A. Sage Publication Company.

Greenberg, Levald dan Baron, Robert 2000, Perilaku Organisasi, Jakarta Prentice Hall.

Hariandja, Marihot Tua Efendi, 2005. Manajemen Sumber Daya manusia, Jakarta, Grasindo Cetakan ke 3.

Hasibuan, S, P, Malayu, 2007, Manajemen Sumber Daya Manusia Dasar dan Kunci Keberhasilan, Jakarta : PT, Toko Gunung Agung,

Hasibuan, S, P, Malayu, 2011, Manajemen Sumber Daya Manusia Dasar dan Kunci Keberhasilan, Jakarta : PT, Toko Gunung Agung,

Hesti,Arlich Arifani,Sukirno, 2012, Pengaruh pengendalian Intern, kepatuhan dan kompensasi Manajemen terhadap 
perilaku etis karyawan, Studi Kasus PT.Adi Satria Abadi Yogyakarta Jurnal Nominal Vol.1, Nomor 1.

Hoy,W.K.\& Miskel, C. G. 2005, Educational Administration Theory, Research and Practice, New York:Random Haose, Inc

Husaini Usman, 2010. Manajemen Riset dan pendidikan, Jakarta, Bumi Aksara.

Irawaty, A. Kohar, 2008 Kosep Kepemimpinan dalam perubahan Organisasi, Studi kasus pada Perpustakaan Perguruan tinggi Universitas Sumatera Utara, Vol 4 Nomor 1.

Ismangil. W. Priono. 2006. Pertumbuhan kewirausahaan koperasi melalui pengembangan unit usaha yang fleksibel dan independen, Infokop, 29XXII- hal 72-76.

Jajang, W. Mahri, 2010. Pelayanan dan manfaat Koperasi serta pengaruhnya terhadap partisipasi anggota (Studikasus koperasi produsen tahu tempe kabupaten Tasikmalaya, Tasikmalaya. Fak. Ekonomi Univ Pendidikan Nasional.

Jogiyanto, 2011, Konsep Dan Aplikasi Structural Equation Modeling, Berbasis Varian Dalam Penelitian Bisnis, Yogyakarta, YKPN.

Jonathan Sarwono, 2007. Analisis Jalur untuk Riset Bisnis dengan SPSS, Yogyakarta, Andi Offset.

Juanda, B. 2007. Operation Research Modul Kuliah Metodologi Penelitian dan Pemodelan Ekonomi FEM IPB, Departemen Ilmu Ekonomi.

Juanda, B. 2009. Ekonometrika: Permodelan dan pendugaan. Bogor,IPB,Press.

Kartono, Kartini, 2010, Pemimpin dan Kepemimpinan, Jakarta, PT. Rajawali Pers
Luthan, Fred, 2006 Perilaku Organisasi, Diterjemahkan oleh, Vivin, Andika, Yuwono dkk, edisi pertama, Yogyakarta. Penerbit Andi

Mangkunegara (2004) Manajemen Sumber Daya Manusia Perusahaan, Bandung PT. Remaja Rosdakarya.

Mariam Budiardjo. 2009, Uji Validitas dan reliabilitas politik, jakarta, PT.Gramedia Pustaka Utama.

Maulizar, Said Musnadi, Muklis, 2012. Pengaruh Kepemimpinan Transaksional dan Transformasional terhadap kinerja karyawan, Bank Syariah Mandiri cabang banda, jurnal Pascasarjana Universitas Syahkuala Vol 1 Nomor 1.

Moelyono Djokosantoso, 2008, More About Beyond Leadership, Jakarta,PT. Elex Media Komputindo

Muhamad Ali Saifuddin 2004, Standarisasi Kompetensi Nasional

Muwarni R. Santoso, 2006. Statistik Terapan, Tekhnik Analisis Data, Jakarta, PPs UHAMKA

Nawawi, Usman, 2008, Sumber Daya Manusia, Jakarta, Gunung Agung.

Ndraha Alizuzuhu, 2002 Teori Pengembangan Sumber Daya Manusia, Rineka Cipta Jakarta.

Noe, A. Raymond, 2005, Employee Training and Development, New york, Mc Graw Hill

Northouse, P. G, 2007, Leadership Theory and Practice, Fourth Edition, London,Sage Publication.

Nugroho Buana Agung, 2005. Strategi Jitu Memilih Metode Statistik Penelitian, Yogyakarta, Andi Offset.

Nur Hafida, 2010. Analisis Implimentasi peran Kepemimpinan, Top Maneger sebagai upaya untuk meningkatkan Motivasi 
kerja karyawan dalam prespektif teori hirarki kebutuhan Maslow pada KUD Kab Malang, Jurna

Robbins, 2008 The Truth About Managing People, Second Edition Upper Sadle River, New Jersey: Pearson Education,Inc.

Santoso, Singgih, 2011, Structural Equation Model (SEM), Konsep dan Aplikasi dengan AMOS 18, Jakarta, PT. Lex Media Komputindo.

Sarwono, Jonathan, 2007. Analisis Jalur untuk Riset Bisnis, Yogyakarta, Andi Offset.

Sedarmayanti, 2008 Sumber Daya Manusia dan Produktivitas Kerja, Bandung, CV.Mandar Maju

Zamzam, Fakhry, Havis Aravik, 2016. Manajemen SDM Berbasis Syariah, Bogor: CV. RWTC Success

Zamzam, Fakhry, 2015, Teknik Dasar Penulisan Proposal Tesis, Palembang, Penerbit Noerfikri. 